\title{
CONTRIBUTION OF PIEZOCISION IN ORAL SURGERY: THE EXAMPLE OF THE ACCELERATION OF ORTHODONTIC MOVEMENTS
}

\author{
Thonnart François $^{1 \mathrm{a}^{*}}$, Systermans $\operatorname{Simon}^{2 \mathrm{~b}}$, $_{\text {, Gilon Yves }}^{2 c}$ (B) \\ ${ }^{1}$ Department of Plastic and Maxillofacial Surgery, CHU Liège, Belgium \\ ${ }^{2}$ Department of Maxillofacial Surgery, ZOL Genk, Belgium \\ ${ }^{a}$ MD, DDS, Maxillofacial Surgery Resident; e-mail: francois-thonnart@hotmail.com; ORCIDiD: https://orcid.org/0000-0001-9382-8699 \\ ${ }^{b}$ MD, DDS, PhD, Professor, Maxillofacial Surgeon; e-mail: yves.gilon@chuliege.be; ORCIDiD: https://orcid.org/0000-0002-1991-5951 \\ 'MD, DDS, Maxillofacial Surgery Resident; e-mail: simon.systermans@chuliege.be; ORCIDiD: https://orcid.org/ 0000-0002-6740-8372
}

\begin{abstract}
do) https://doi.org/10.25241/stomaeduj.2021.8(3).art.4

Introduction Patients are more demanding of short or less invasive interventions. Piezocision responds well to this demand, particularly in the case of piezo-guided corticotomy to accelerate orthodontic movements. Different surgical approaches are described to shorten orthodontic procedures. Corticotomy is a surgical process where osteotomies are realized at the level of the cortical part of the bone.

Objective The aim of this work is to review the contribution of piezocision in oral surgery, using as example a review over the current results of piezocision on the acceleration of orthodontic movements.

Data sources The articles referenced and used in this article come from the PubMed database. The searched keywords were "piezocision" alone or in combination with "orthodontics".

Study selection This search resulted in 44 available articles. Subsequently, 6 randomized controlled trials were selected based on relevance, journal, and publication date. Four Randomized Controlled Trials and two Controlled Clinical Trials were studied.

Data extraction The reviewer assessed each article for their relevance and methodology. The 6 studies compared the time savings between conventional orthodontic treatment (control group) and orthodontic treatment combined with piezocision surgery (test group).

Data synthesis Piezocision corticotomy reduces the operation and the postoperative period and increases the acceptance of corticotomies and their indications.
\end{abstract}

\section{KEYWORDS}

Piezocision ; Orthodontics ; Corticotomy ; Oral Surgery ; Minimally Invasive.

\section{INTRODUCTION}

Originally, piezosurgery was developed to allow cutting hard structures without affecting soft structures, with an ultrasound instrumentation. Bone cutting is performed by high frequency micromovements generated by the piezoelectric handpiece, the piezotome. The back and forth motion transmitted to a cutting insert creates a cutting effect. Over the past decades, numerous scientific articles have illustrated the numerous indications of piezocision in oral surgery, implant surgery, cranio-maxillofacial surgery and other surgical disciplines. The main advantages and characteristics of piezocision are the selective cutting of the bone without damaging adjacent soft tissues such as vessels, nerves, mucous membranes, but also to reach difficult access areas via angled inserts compared to conventional instrumentation, and to cut without generating signifi- cant exothermic reaction. The use of angled inserts improves the visibility of the operating field. Therefore, piezoelectric surgery is a safe, precise and atraumatic technique.

In our oral and maxillofacial surgery practice, the piezotome is currently taking an important place. It is particularly used in our department in preimplant surgery for maxillary ridge expansion, opening the bone windows during the sinus lift, during ramic, symphyseal, tuberosal or cranial parietal harvesting and during the lateralization surgery of the inferior alveolar nerve. The piezotome is also used in maxi-llofacial surgery for mandibulectomy and costochondral harvesting (temporomandibular ankylosis treatment, rhinoplasties), and for free fibula flaps. It is also used for condylectomies and complicated mandibular sagittal osteotomies with malposition of the inferior alveolar nerve. In oral surgery, the piezotome is used in our practice for retrograde 
endodontic surgeries, cyst removal but also to accelerate orthodontic movements.

Orthodontics is a dental discipline that aims to correct the dental occlusion and/or the positioning of the jaws and teeth, using various removable or fixed devices. The long duration of orthodontic treatments is one of the most common complaints of patients undergoing orthodontic treatment. In addition, longer treatments can increase the risk of complications such as caries, periodontal problems and root resorption.

Various surgical approaches have been described to accelerate tooth movement. Invasive procedures such as corticotomies with periodontal flaps have shown good results in decreasing treatment times in orthodontics [1-2].

To reduce the invasiveness of corticotomies, a minimally invasive surgical procedure has been introduced. This consists of making transmucosal cortical incisions without flaps using a piezotome. This technique involves micro-incisions and small corticotomies. Localized decortication induces a demineralization-remineralization process described as regional acceleratory phenomenon (RAP). The induced corticotomy at the bone level is followed by an increase in bone turnover and a decrease in bone mineral.

The aim of this work is to explain the contribution of piezocision in oral surgery through piezocision corticotomy.

\section{MATERIALS AND METHODS}

The articles referenced and used in this article come from the Pubmed database. The searched keywords were "piezocision" alone or in combination with "orthodontics". This search resulted in 44 available articles. Subsequently, 6 randomized controlled trials were selected based on relevance, journal, and publication date. Each study was conducted on healthy patients and analyzed the effectiveness of piezocision on accelerating orthodontic movements.

\section{RESULTS}

Four Randomized Controlled Trials and two Controlled Clinical Trials were studied. The 6 studies compared the time savings between conventional orthodontic treatment (control group) and orthodontic treatment combined with piezocision surgery (test group).

\subsection{Characteristics of the studies}

The general information from the studies is summarized in Table 1. Of the 6 articles, 4 are RCT [3-4-6-8] and 2 are CCT [5-7]. All studies included 131 patients. Each study presented a group treated with electric piezocision and another "control" group with conventional orthodontic movement. One study [5] compared the efficacy of conventional corticotomy to piezocision. The studies by Uribe, Gibreal, and Charavet focus on tooth alignment, while the studies by Abbas and Aksakalli investigate canine distalization in premolar extraction.

\subsection{Orthondontic movements}

The study by Charavet et al [6] showed a decrease of $43 \%$ in orthodontic time in the piezocision group compared to the control group, compared to $59 \%$ in the study [4]. The differences between the two groups in study [6] increased in time until full alignment but decreased for final adjustments.

Study [3] showed no significant difference between the two groups. The duration of canine distalization in study [7] is reduced in the piezocision group.

In addition, the study by Abbas et al [5] found a higher rate of movement in the corticotomy group compared with the piezocision group during weeks $2,4,10,12$ after surgery. The 2019 study by Charavet et al [8] shows a $36 \%$ acceleration of treatment for the piezocision group compared with the control group.

\begin{tabular}{|c|c|c|c|c|c|c|}
\hline Study name & $\begin{array}{l}\text { Study } \\
\text { type }\end{array}$ & Number & Group & Intervention type & $\begin{array}{l}\text { Type of orthodontic } \\
\text { movements }\end{array}$ & Origins \\
\hline Uribe (2013) [8] & RCT & $n=29$ & $\begin{array}{l}\text { Piezocision: M:6; W:10; age: } 30 \\
\text { Control: M:6; W:7; age } 29.4\end{array}$ & $\begin{array}{l}\text { Piezocision: piezocision + orthodontic movement } \\
\text { Control: Orthodontic movement only }\end{array}$ & $\begin{array}{l}\text { Anterior alignment due to } \\
\text { crowding of the maxilla ( } 3 \text { to } 3 \text { ) }\end{array}$ & USA \\
\hline Gibreal (2019) [4] & RCT & $n=34$ & $\begin{array}{l}\text { Piezocision: } n=17 \\
\text { Control: } n=17\end{array}$ & $\begin{array}{l}\text { Piezocision: piezocision + orthodontic movement } \\
\text { Control: Orthodontic movement only }\end{array}$ & $\begin{array}{l}\text { Anterior alignment due to } \\
\text { crowding of the maxilla ( } 3 \text { to } 3 \text { ) }\end{array}$ & Syria \\
\hline Abbas (2016) [5] & $\mathrm{CCT}$ & $n=20$ & $\begin{array}{l}\text { Group } 1: n=10 \\
\text { Group 2: } n=10\end{array}$ & $\begin{array}{l}\text { Group 1: one-sided corticotomy with } \\
\text { contralateral control group } \\
\text { Group 2: one-sided piezocision with contralateral } \\
\text { control group }\end{array}$ & Distalization of a maxillary canine & Egypt \\
\hline Charavet (2016) [6] & RCT & $n=24$ & $\begin{array}{l}\text { Piezocision: } n=12 \\
\text { Control: } n=12\end{array}$ & $\begin{array}{l}\text { Piezocision: piezocision + orthodontic movement } \\
\text { Control : Orthodontic movement only }\end{array}$ & $\begin{array}{l}\text { Anterior alignment due to } \\
\text { crowding of the upper and lower } \\
\text { jaws ( } 3 \text { to } 3 \text { ) }\end{array}$ & Belgium \\
\hline Aksakalli (2016) [7] & CCT & $n=10$ & I & $\begin{array}{l}\text { Piezocision: piezocision + orthodontic movement } \\
\text { Control : Orthodontic movement only }\end{array}$ & Distalization of a maxillary canine & Turkey \\
\hline Charavet (2019) [8] & RCT & $n=24$ & $\begin{array}{l}\text { Piezocision: } n=12 \\
\text { Control: } n=12\end{array}$ & $\begin{array}{l}\text { Piezocision: piezocision + orthodontic movement } \\
\text { Control: Orthodontic movement only }\end{array}$ & $\begin{array}{l}\text { Anterior alignment due to } \\
\text { crowding of the upper and lower } \\
\text { jaws ( } 3 \text { to } 3 \text { ) }\end{array}$ & Belgium \\
\hline
\end{tabular}

Table 3. Studies descriptions. 
A summary table (Table 2) compares the time gains for the test groups versus the control groups.

\begin{tabular}{|l|c|c|}
\hline \multicolumn{1}{|c|}{ Studies } & N & Saves time in orthodontic treatment (\%) \\
\hline Uribe, et al. 2017 [3] & 41 & Not significant \\
\hline Gibreal, et al. 2019 [4] & 36 & $59 \%$ \\
\hline Charavet, et al. 2019 [8] & 24 & $43 \%$ \\
\hline Charavet, et al. 2016 [6] & 24 & $36 \%$ \\
\hline Abbas, et al. 2016 [5] & 20 & $/$ \\
\hline Aksakalli, et al 2016 [7] & 10 & $63 \%$ \\
\hline
\end{tabular}

ITable 2. Comparison of time savings according to the analyzed studies.

\subsection{Surgical approach}

The surgical protocol is based on a flapless piezocision procedure. This technique consists in making vertical interproximal microincisions $4 \mathrm{~mm}$ above each papilla. The length of the incisions varies according to the studies from 5 to $8 \mathrm{~mm}$ [6-8] and $4 \mathrm{~mm}$ [3]. After the incisions, the gingiva is elevated to visua-lize the bone and adjacent roots. A corticotomy line is then made with a piezoelectric instrument. The line also varies according to the studies, from $5 \mathrm{~mm}$ long and $3 \mathrm{~mm}$ deep for Charavet et al. [6-8] and $1 \mathrm{~mm}$ deep for Uribe et Al [3]. The incisions are sutured with absorbable suture.

\subsection{Periodontal parameters}

All periodontal parameters were comparable between the piezocision and test groups at the end of the treatment in the studies[5-6-7-8].

For 3 patients ( 2 in the control group and 1 in the test group) in the study [6], a non-significant increase in recession was observed between the interval at the beginning of the treatment and the end of the treatment.

The studies by Charavet et al [6-8] investigated the visibility of vertical scars in the piezocision groups. Study [6] observed persistent scarring in $50 \%$ of patients with piezocision. In $33 \%$ of cases, the scar was as a punt and in $17 \%$ of cases, in the form of a line. The 2019 study shows a visible scar in $66 \%$ of the patients treated with piezocision.

\subsection{Root resorptions}

Abbas et al [5] showed that there were no differences in root resorptions between the corticotomy group and the piezocision group. However, the contralateral control group shows greater root resorptions of the canine than the experimental groups (piezocision and corticotomy).

Studies [6-8] do not show an increase in root resorptions in each group.

\subsection{Patient-centered outcomes}

Study [6] did not show any significant differences between the two groups consumption of paracetamol. The level of satisfaction was significantly higher in the piezocision group compared to the control group.

\section{DISCUSSION}

The analysis of the results shows an acceleration of orthodontic treatment in 5 of the 6 clinical trials analyzed, ranging from 36 to $63 \%$ (Table 2). According to Uribe et al. [3], the results of his study do not show a significant difference in the time required to correct a mandibular anterior crowding between the two groups.

The lack of significant time savings in orthodontic treatment in the Uribe et al. [3] study is probably related to the surgical technique. Indeed, the corticotomy is only $1 \mathrm{~mm}$ deep and $3 \mathrm{~mm}$ high, compared to the $3 \mathrm{~mm}$ and $5 \mathrm{~mm}$ found in the studies of Charavet [6-8] and Gibreal [4].

In addition, the studies by Charavet et al. and Gibreal et al. perform 5 vertical incisions up to the canine-premolar interdental space while Uribe et al. perform 3 vertical incisions, stopping between the canine and lateral incisor. The difference between the two RCTs by Charavet et al. may be explained by the use of different Brackets system, CAD/CAM for the 2019 study.

The study by Gibreal et al. shows a greater time gain than the 2 studies by Charavet et al. The improvement in time gain for orthodontic tooth movements observed is probably related to the severity of the anterior crowding. In the Gibreal et al. study, severe anterior crowding required prior extraction, which probably increased the RAP effect.

Based on the results of the studies above and the literature cited above, the effectiveness of bone decortication in accelerating tooth movement is progressive and effective for 3 months after surgery, with greater effectiveness in the maxilla. This effectiveness of piezocision is observed when the first arch is placed 1 to 2 weeks before surgery and when the corticotomy is at least $3 \mathrm{~mm}$ deep and 5 to $8 \mathrm{~mm}$ long. In addition, the patient should be recalled every 2 weeks to activate the fixed appliance if possible because of the limited effect of the RAP [4]. A review of the literature by Mertens et al. [9] shows interesting results of corticotomies depending on the indications. All of them seem to go in the direction of an acceleration of dental movements. However, few studies have been performed with a control group treated with fixed orthodontics, without surgery. Therefore, the number of reviews supporting that the use of corticotomies reduces orthodontic treatment time is limited.

According to Charavet et al. [6-8], there is a visible scar (either punctiform or linear) in 50 to $66 \%$ of the subjects who have undergone piezocision. Therefore, upper jaw piezocision is not recommended for patients with a gummy smile.

Furthermore, an interradicular proximity of less than $2 \mathrm{~mm}$ is a contraindication to corticotomy6. Means such as CBCT, surgical guides [10] or retroalveolar radiographs with opaque interradicular wires can be used to avoid root effraction. These tools can also be 
used to prevent damage to anatomical structures such as the maxillary sinus or the mental foramen. All periodontal parameters appeared to be stable in the different studies. However, 3 patients with pre-existing oral recessions showed an increase in recessions [8]. Therefore, mucogingival techniques combined or not with piezocision may be interesting to prevent gingival recession. A bone grafting technique associated with piezocision was performed in a study by Charavet and Lecloux [11]. This technique has allowed a thickening of the vestibular bone in a class II patient and thus prevented the aggravation of bone dehiscence and the appearance of gingival recession.

According to the study by Angelo Troedban [12], the use of surgical ultrasound devices in reduction rhinoplasty has shown a decrease in postsurgical morbidity and significantly increases overall patient satisfaction. Piezotome rhinoplasty could reduce the need for secondary corrective rhinoplasties, and piezotomes could be the surgical instrument of choice in facial hard tissue cosmetic surgery as they already are in oral surgery.

Relating to preimplant sinus surgery, numerous studies [13-14] have shown a lower rate of Schneider's sinus membrane perforation using piezoelectric instruments compared with conventional rotary instrumentation.

In orthognathic surgery, most surgical trauma occurs especially during osteotomy. Therefore, any surgical tool such as the piezotome that can provide a safe and precise cut is an excellent option. It has several disadvantages: reduced ability to cut dense bone, increased time to perform an osteotomy [15] and additional cost [16]. The neurosensory effect of the piezotome is the main factor studied by several authors [16], especially on the inferior alveolar nerve during sagittal osteotomy of the lower jaw. Most studies report little or no nerve damage using piezotomy surgery. Only one comparative study finds less nerve disruption after inferior sagittal osteotomy using conventional rotary handpiece instrumentation [16].

\section{CONCLUSION}

Piezocision corticotomy seems to be an attractive technique to reduce the time of orthodontic treatments. Compared to corticotomies, it reduces the operation and the postoperative period and increases the acceptance of corticotomies and their indications.

However, given the presence of vertical scars in more than $50 \%$ of cases, it remains contraindicated in patients with a gummy smile.

These examples confirm the interest of piezosurgery in oral and maxillofacial surgery, at a time when the demand for less invasive treatments is growing. The indications for the piezotome are becoming more and more extensive, which makes it an instrument of choice, indispensable in our practice.

\section{ACKNOWLEDGMENTS}

There are no conflicts of interest and no financial interests to be disclosed.

\section{AUTHOR CONTRIBUTIONS}

FT, SS: wrote the manuscript in consultation with YG. All authors provided critical feedback and helped shape the research and the manuscript. YG: aided in interpreting the results.

\section{REFERENCES}

1. Gkantidis N, Mistakidis I, Kouskoura T, Pandis N. Effectiveness of non-conventional methods for accelerated orthodontic tooth movement: a systematic review and meta-analysis. J Dent. 2014 Oct;42(10):1300-19. doi: 10.1016/j.jdent.2014.07.013. Epub 2014 Jul 27. PMID: 25072362.

Full text link PubMed Google Scholar Scopus

2. Patterson BM, Dalci O, Darendeliler MA, Papadopoulou AK. Corticotomies and orthodontic tooth movement: A systematic review. J Oral Maxillofac Surg. 2016 Mar;74(3):453-73. doi: 10.1016/j.joms.2015.10.011. Epub 2015 Oct 24. PMID: 26608454. Full text link PubMed Google Scholar CrossRef WoS 3. Uribe F, Davoody L, Mehr R, et al. Efficiency of piezotomecorticision assisted orthodontics in alleviating mandibular anterior crowding-a randomized clinical trial. Eur J Orthod. 2017 Nov 30;39(6):595-600. doi: 10.1093/ejo/cjw091. PMID: 28371882. Full text link PubMed Google Scholar Scopus WoS

4. Gibreal O, Hajeer MY, Brad B. Efficacy of piezocision-based flapless corticotomy in the orthodontic correction of severely crowded lower anterior teeth: a randomized controlled trial. Eur J Orthod. 2019 Mar 29;41(2):188-195. doi: 10.1093/ejo/cjy042. PMID: 29931294.

Full text link PubMed Google Scholar Scopus WoS

5. Abbas NH, Sabet NE, Hassan IT. Evaluation of corticotomy-facilitated orthodontics and piezocision in rapid canine retraction. Am J Orthod Dentofacial Orthop. 2016 Apr;149(4):473-80. doi: 10.1016/j.ajodo.2015.09.029. PMID: 27021451.

Full text link PubMed Google Scholar Scopus WoS
6. Charavet C, Lecloux G, Bruwier A, et al. Localized piezoelectric alveolar decortication for orthodontic treatment in adults: A Randomized Controlled Trial. J Dent Res. 2016 Aug;95(9):10039. doi: 10.1177/0022034516645066. Epub 2016 Apr 29. PMID: 27129491.

Full text link PubMed Google Scholar

7. Aksakalli S, Calik B, Kara B, Ezirganli S. Accelerated tooth movement with piezocision and its periodontal-transversal effects in patients with Class II malocclusion. Angle Orthod. 2016 Jan; 86(1):59-65. doi: 10.2319/012215-49.1. Epub 2015 May 19. PMID: 25989211.

Full text link PubMed Google Scholar WoS

8. Charavet C, Lecloux G, Jackers N, et al. Piezocision-assisted orthodontic treatment using CAD/CAM customized orthodontic appliances: a randomized controlled trial in adults. Eur J Orthod. 2019 Sep 21;41(5):495-501. doi: 10.1093/ejo/cjy082. PMID: 30649257.

Full text link PubMed Google Scholar

9. Mertens B, Angioni C, Orti V, Canal P. Collaboration between periodontics and orthodontics: interest of alveolar corticotomies and piezocision. Review of literature]. Orthod Fr. 2017 Jun;88(2):179-191. French. doi: 10.1051/orthodfr/2017010. Epub 2017 Jun 9. PMID: 28597838

Full text link PubMed Google Scholar

10. Strippoli J, Durand R, Schmittbuhl M, et al. Pain and quality of life in patients undergoing guided piezocorticision- assisted orthodontic treatment. J Clin Orthod. 2017 Dec;51(12):792-799. PMID: 29364825.

PubMed Google Scholar $\underline{\text { Scopus }}$ 
11. Charavet C, Lecloux G, Bruwier A, et al. Selective piezocision-assisted orthodontic treatment combined with minimally invasive alveolar bone regeneration: A proof-of-concept. Int Orthod. 2018 Dec;16(4):652-664. doi: 10.1016/j.ortho.2018.09.021.

Epub 2018 Nov 1. PMID: 30391131 . Full text link PubMed Google Scholar Scopus WoS

12. Troedhan A. Piezotome rhinoplasty reduces postsurgical morbidity and enhances patient satisfaction: A multidisciplinary clinical Study. J Oral Maxillofac Surg. 2016 Aug;74(8):1659.e11659.e11. doi: 10.1016/j.joms.2016.04.013. Epub 2016 Apr 23. PMID: 27186871.

PubMed Google Scholar

13. Wallace SS, Mazor Z, Froum SJ, et al. Schneiderian membrane perforation rate during sinus elevation using piezosurgery: clinical results of 100 consecutive cases. Int J Periodontics Restorative Dent. 2007 Oct;27(5):413-419. PMID: 17990437. Full text link PubMed Google Scholar Scopus WoS

14. Testori T, Wallace SS, Del Fabbro M, et al. Repair of large sinus membrane perforations using stabilized collagen barrier membranes: surgical techniques with histologic and radiogra- phic evidence of success. Int J Periodontics Restorative Dent. 2008 Feb;28(1):9-17. PMID: 18351198

Full text link PubMed Google Scholar Scopus WoS

15. Bianchi A, Badiali G, Piersanti L, Marchetti C. Computerassisted piezoelectric surgery: a navigated approach toward performance of craniomaxillofacial osteotomies. J Craniofac Surg. 2015 May;26(3):867-872. doi: 10.1097/SCS.0000000000001360. PMID: 25915675.

Full text link PubMed Google Scholar Scopus WoS

16. AlAsseri N, Swennen G. Minimally invasive orthognathic surgery: a systematic review. Int J Oral Maxillofac Surg. 2018 Oct;47(10):1299-1310. doi: 10.1016/j.ijom.2018.04.017. Epub 2018 May 29. PMID: 29857982.

Full text link PubMed Google Scholar Scopus WoS

17. Shirota T, Kamatani T, Yamaguchi T, et al. Effectiveness of piezoelectric surgery in reducing surgical complications after bilateral sagittal split osteotomy. Br J Oral Maxillofac Surg. 2014 Mar;52(3):219-222. doi: 10.1016/j.bjoms.2013.11.015. Epub 2014 Jan 3. PMID: 24388635.

Full text link PubMed Google Scholar Scopus WoS

\section{François THONNART}

MD, DDS, Maxillofacial Surgery Resident Department of Maxillofacial Surgery ZOL Genk, Belgium

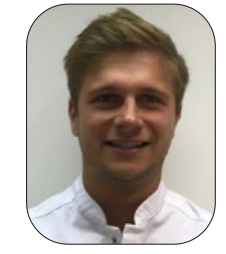

Dr. François Thonnart is a resident in Oral and Maxillofacial Surgery at the University of Liège, Liège, Belgium. He has a clinical focus on the head and neck oncology, orthognatic and dento-alveolar surgery. He currently works as resident in Ziekenhuis Oost Limburg in Genk, Limburg, Belgium.

\section{Questions}

\section{The effectiveness of piezocision is observed when:}

$\square$ a. The first arch is placed 3 weeks after the surgery;

b. The corticotomy is $3-4 \mathrm{~mm}$ long;

ac. The corticotomy is minimum $3 \mathrm{~mm}$ deep;

$\square$ d. The corticotomy is $1-2 \mathrm{~mm}$ deep.

\section{In Charavet's study, there is a visible scar after piezocision in:}

口a. 50 to $66 \%$;

ab. 35 to $45 \%$;

ac. 0 to $10 \%$;

ad. 95 to $100 \%$.

\section{The use of surgical ultrasound devices has shown:}

$\square$ a. A higher rate of Schneider's sinus membrane perforation;

b. No increase in patient satisfaction for rhinoplasty;

ac. A decrease in postsurgical morbidity;

$\square d$. It can increase the need for secondary corrective rhinoplasties.

\section{Piezotome:}

$\square$ a. Is not able to cut dense bone;

$\square$ b. Reduces the risk of nerve damage;

ac. Decreases the time to perform an osteotomy;

$\square \mathrm{d}$. Increases the time of orthodontic treatments. 